\title{
Dynamic, playful and productive literacies
}

\begin{abstract}
This paper reflects on recent projects in a variety of media forms, in both formal and informal educational settings, discussing ways of expanding our notions of literacy practices which reflect their place in the wider lived experience of digital culture. We have collected these reflections under three headings. The first of these, Dynamic Literacies, presents an overarching view of literacy as both ideological, following the 'new literacy studies', and dynamic, incorporating both semiotic and sociocultural versions of literacy in ways which reflect the changing nature of lived experience in the digital age. The second strand, Productive Literacies, constructs an argument around digital making practices with younger learners which views these as media crafting, critique and artistry. The third strand, Playful Literacies, explores recent projects which are located in games and game authoring practices as a specific example of connecting pedagogy to contemporary media forms and learner agency in formal and informal settings. Taken together, the three perspectives allow for common ground to be established between multimodal production practices, whilst providing suggestions for framing literacy pedagogy in response to the pervasive use of media and technology in contemporary digital culture.
\end{abstract}

KEY Words: dynamic literacies, media production, play, game authoring.

To cite this work, please refer to the published article:

Cannon, M., J. Potter, and A. Burn. 2018. "Dynamic, Playful and Productive Literacies." Changing English: Studies in Culture and Education 25 (2): 183-99. 


\title{
Dynamic, playful and productive literacies
}

\author{
DYNAMIC LITERACIES
}

Recent work in the field of media education and literacy studies (Potter and McDougall 2017) has suggested that 'dynamic' might be an appropriate term for bringing together a number of versions of 'literacy' whose origins lie in the 'new literacy studies' (Gee 2015; Street 1995, 2003) or 'multiliteracies' (Cope and Kalantzis 2000) as well as moving forward and enlarging the definition of 'literacy' itself. These newer versions of literacy acknowledge the changing nature of meaning-making and communication which have been brought about by the pervasive use of digital technologies, as well as the consequent and parallel changes to social arrangements and practices inherent in the use of new artefacts and devices (Lievrouw and Livingstone 2006). However, in many educational systems, they exist alongside, but essentially invisible in, versions of the curriculum which focus on narrower definitions, and which are used to justify performative measures, in which learners discover their 'level' as something which stands for them and their ranking in the 'autonomous' vision of literacy (Street 2003; Yandell 2014).

Digital modes of communication are frequently positioned in relation to 'literacy' as a residual category. It is possible to find multiple versions of 'literacy' in contemporary discourse which acknowledge the changing nature of meaning-making. Among these would be: media literacy, digital literacy, multimodal literacy, information literacy and many more. They have been tactically and helpfully used by academics and campaigning groups aligned with expanding the definition of literacy more widely. At the same time, in curriculum documents, teacher education texts and so on, they can be misunderstood and misinterpreted as markers of what is left after we have defined literacy as print. In other words, the turn towards 'media', the 'digital' and other such versions of literacy is possible only after we have mastered the perceived real literacy: printed text, its consumption and production. This response to the changed practices, texts and artefacts around acts of meaning-making in the digital age is clearly inadequate. Media are central to the dominant modes of communication; they are not part of any residual category and an understanding of the way they work in the world is essential. A curriculum would be better designed by recognising that all literacy is 'multimodal' and that 'multimodality' as a theory of communicative practices should shape what happens in educational systems in the $21^{\text {st }}$ century. At the same time, all meaning-making is ideological and situated and so there is a further pressing need to employ a sociocultural frame of understanding to these processes and spaces. Finally, all of these practices are located in systems in which human and non-human agents, inside and outside school, exert a strong influence over literacy events in the space of the classroom and over the agency of the social actors therein. Emergent writing is producing useful commentary on, and new theory about, these networks and assemblages of practices, bodies and artefacts in learning spaces.

At this point, we should insert the caveat that we are not arguing that 'othered' forms of literacy: media literacy and digital literacy for example, are somehow more important than print. Indeed, children, young people and everyone else are arguably reading more than ever and in more varied ways; likewise, they are producing more text than ever before, in different environments, for different audiences. The argument we are making is that these textual forms exist alongside and within a system in which the screen, and especially the touchscreen, is the dominant site of consumption and production of meaning-making of all kinds: printed, visual (still and moving image), audio. All literacy is multimodal and it is all socially produced and in a constant state of change. It is all dynamic and, in this way, we see dynamic not as one more residual category of literacy, but as a term which encompasses and enlarges the overall vision of 'literacy'. 
'Dynamic' as an antonym of 'static' is also a useful signal of a political and ideological opposition to curriculum designs which position students in a narrow and performative experience which is divorced from their actual experience of meaning making as situated and alive. In 2013, for example, all reference to visual culture and the moving image was removed from the English curriculum for children in primary schools. Blind-siding the dominant mode of communication of the digital age, we argue, represents a very unambitious vision of the curriculum. Instead, we suggest that curriculum experiences based on those dominant modes of communication could become fruitful locations of pedagogical development: these could include, but not be limited to experiences in digital media arts of all kinds. Of course, many schools and after-school clubs do indeed recognise these as creative and beneficial experiences in spite of the narrowness of the curriculum definitions. The push and pull on pedagogy of the definition of literacy which is in play in curriculum requirements exerts a heavy influence on what goes on in the school and/or after-school club. But in some learning spaces the dynamic vision pertains and is widening and re-invigorating the curriculum on offer. In the sections which follow we examine some spaces in which this is occurring and make some suggestions based on our research in the field.

A few years ago, a research project called 'Persistence of Vision' investigated the connected nature of learning about non-narrative poetry and making animation with younger learners (Bazalgette, Parry, and Potter 2011). It reported on an initiative funded by 3 rural authorities and the UK Film Council and co-ordinated by the Media Education Association in 18 primary schools. There has been a tradition of connecting print literacy and media learning (Parry 2013) with the latter usually in service to the former as an enabler or motivator. The aim of this particular project, however, was to go beyond the notion of learning traditional literacy through media production practice to suggest that, just as in lived experience, being media literate, both as consumer and producer, shares many of the characteristics of being print literate. The hypothesis was that it should be possible for 'literacy' gains in the widest possible sense to be the intended outcome in a project which fostered simultaneous creation of short animated sequences using a webcam and laptop. The writing and the animation were in a symbiotic relationship throughout with poetry providing the inspiration for the images used alongside more abstract sources of inspiration (audio clips of rain, wind and so on) which in turn were reverse engineered back into writing. Reflecting on this project later, teachers reported that there had indeed been gains in writing across the board in the different locations but we also found that there had been connections with new knowledge domains in the making of meaning; working with the time-based and intensive, imagefocused nature of making animation had corollaries in the metre, register and image focus of non-narrative poetry. As we wrote at the time, '....in textual terms, at both functional and formal level, the poetry supported the animation and vice versa.' (Bazalgette et al. 2011). Both forms were in a dynamic relationship with one another in the space of the primary classroom, moving even beyond the motivating factor of working in the culturally significant form of the animated moving image.

The project sits within a tradition of work exploring media production in spaces of learning, particularly where this has been connected to: understanding pedagogy around meaningmaking systems in an enlarged version of literacy (Burn 2009; Burn and Durran 2007; Burn and Parker 2003); policy and how this can best be operationalized (Bazalgette 1989; Marsh and Bearne 2008); widening the conception of literacy with examples and programmes of study (BFI 2008; FLAG 2015); thinking about production as craft and artistry with a whole set of consequences for pedagogy (Cannon 2018); new literacies as everyday practices (Lankshear and Knobel 2006); multimodality as a site for understanding literacy in a digital age (Bezemer and Kress 2016; Jewitt 2005; Pahl 2009) and media education and its relationship to technology (Buckingham 2003; 2007). 
There is a disconnect between the expectations and demands placed on children and young people in static systems and the range of skills and dispositions evident in their use in the flow of dynamic literacies beyond school, in the use of social media and more. We've used the term 'disconnect' to suggest that both spaces have things to offer all the social actors involved in teaching and learning. Is there a way to move across the boundary between home and school, bringing not only culturally resonant and significant texts but also powerful knowledge and 'porous expertise' from beyond the educational setting? (McDougall \& Potter, 2015; Potter, 2011). This is an adaptation appropriate to the digital age of much thinking in the teaching of English and literacy at all levels from many writers and academics who have argued for the funds of knowledge and cultural capital of students to be allowed space in the classroom (Haas Dyson, 1997; Marsh \& Millard, 2000; Parry, 2013; Rosen, 1989). However, in some educational technology literature, in the context of the digital, this is occasionally simplified into a generational issue (Prensky, 2005) which is an idea which is very hard to shift, though there are serious critical voices who have taken issue with this stance (Thomas, 2011). In fact, what we have observed in a range of projects which have been significant in shaping our thinking is not so much a generational issue, as one which concerns understanding the range of critical, creative and cultural forces (Green, 2002) which shape the dynamic around new literacies and learners. These include, of course, the varied social and economic circumstances around them as well as the pedagogical issues inherent in the conception of literacy, as previously discussed.

Far from being a homogenous generation of 'digital natives' (Prensky, 2005), young people in educational institutions are subject to the same material and (some of) the performative forces which impact on the lives and agency of those who teach and work with them. Some will have access to the powerful and dynamic tools of meaning-making and some will not. Some will have access to skillsets and dispositions which are founded on the playful and productive use of certain kinds of technologies, others will be hardly developed at all, beyond, perhaps, being able to post media into social platforms and to share content. In any case, our consideration of their practices and wish to support their productive futures in their engagement with dynamic literacies, is also bounded by our ability to understand (or not) the impact of non-human actors in the network of activities they undertake (Latour, 2005).

In connection with this issue, some recent ways of thinking about education in the context of dynamic literacies is emerging from the field of 'sociomateriality' in the context of media production and creative coding activities in classrooms, paying attention to:

... the arrangements of bodies, devices and locations with respect to discussing literacy events and pedagogy as an orchestration of all of these factors, describing them as sets of real events... (these) studies are seeking to create accounts of 'real' classrooms, in all their messy realities, and the ways in which these are integrated into meaning-making onscreen and in the material spaces of learning.

(Potter and McDougall 2017, 46)

Such studies include those by Cathy Burnett and Guy Merchant in the UK (2014) and Michael Dezuanni in Australia (2015) who have all explored ways of describing the 'assemblages' of human and non-human actors in formal and informal educational settings, in both cases around making new media in productive coding clubs. In so doing they locate such activities in specific spaces in which they occur as 'third spaces' as in Gutierrez's version of culturally negotiated learning spaces (2008) but they go further by involving the additional dynamic of the place of artefacts in the assembling of social practices.

We suggest that these recent ways of thinking are further manifestations of a way to conceptualise literacy as a 'dynamic' which is resistant to static definitions which seek both 
to fossilise pedagogy and to legitimise the narrow target-setting agenda into something which displaces and marginalises the cultural capital of pupils (Alanen, Brooker, and Mayall 2015). For us, the term dynamic literacies mobilises the steps taken by scholars such as Shirley Brice Heath (1983) Brian Street (1995) and James Gee (2004) to build theory and practice around ideological and situated visions of literacy teaching and learning. And...

... we would argue further that dynamic literacies is a term which is both synchronic, inclusive of current situated practices, and diachronic, a term which opens the possibility of movement through time as an incorporated principle. It ... has its own momentum as a sharp contrast with the static nature of the literacy of 'the basics', of performative systems. In other words, it is aligned more closely with the ideological version of literacy because it suggests that literacy is always context-bound and contingent. For the moment, it is a necessary additional term which stands for a version of literacy which is usefully inclusive of various other liminal, spatial and technological literacies gathered together in the 'New Literacy Studies'. More than this, it provides an immediate contrast with the static nature of curriculum and assessment design for literacy in many performative systems.

(Potter and McDougall 2017, 36)

Earlier we outlined the ways in which multimodal synergies between poetry and animation produce rich learning outcomes of more relevance to young people and their lived cultural experiences. The following section borrows from craft discourses to explore how video editing generates a dynamism between the spatial, the material and the cognitive that further demonstrates the nature of literacy as multi-dimensional and socially 'eventful'.

\section{PRODUCTIVE LITERACIES}

Threaded through this article is a commitment to creative media production, which is as intrinsic to media literacy practices as writing is to reading in print culture. As stated, we would like to argue that a holistic view of literacy, one that embraces digital media in all their forms and expressive affordances, is linked to specific social contexts and acts of cultural production. Further, systems of education that privilege print often deny learners the richness of collaborative practice that accompanies the manipulation of the moving image. For example, during the process of film production, learners are engaged in overlapping domains that value and mobilise personal cultural repertoires and performance (Potter 2012). We believe that giving children and young people repeated practical experiences with a range of meaning-making modes enhances their potential for active cultural participation in digital realms.

To deepen understanding of practical media work, conceptual tools are borrowed from sociology and from arts education: namely, from Richard Sennett (2008) and his formulations around craft principles, and Elliot Eisner (2005), a prolific advocate of arts education who recruited the Aristotelian concept of phronesis to illuminate ways of knowing related to the practical. Weaving such theories into teaching and learning with digital media reflects the interdisciplinary nature of this our ideological understanding of modern literacy, one that frames production in terms of craft, critique and artistry. Research findings from a sustained after-school film-making club with Key Stage 2 primary learners (see The Clip Club blog, Cannon 2013a) illustrate the interrelations between these dimensions. It is proposed that through recurrent filmmaking activities the Club's 9- and 10-year-old participants took on the artisanal and creative habits of artists and film-makers. Such qualities model the kind of skills and dispositions one might expect of a proto media literate practitioner operating within a more ambitious vision of literacy. 
The dimension of literacy under discussion in this section relates to the ways in which meanings are made through the assembly, the sequencing and the editing of the moving image. It is proposed here that just as craftspeople and 'form-makers' (Eisner 2005) of all kinds - jewellers, ceramicists, sculptors and carpenters - shape and combine raw materials to produce an artefact for use or display, parallels can be made with the practices of the media-maker. The complex interplay between screen, software, symbolic resources and the human imagination, recalls the versatility of craftspeople as they negotiate tools, materials and contingent conditions. Being literate is articulated here as a sensibility towards a perceptual craft and an attunement to the composition of digital assets. Not only this but the craft metaphor helps us understand the part of literacy that involves the retrieval of cultural memory. As Potter and McDougall (2017) observe, the synchronic and diachronic dimensions of digital making are given due consideration in an understanding of literacy that includes the temporal and cultural continuity with the past.

Sennett offers four principles of craft that are helpfully framed in ways that transfer to other realms. He defines four constituents of the 'intuitive leap' in relation to design and making processes (see Sennett 2008, 210-212) which are useful tools for understanding digital video editing and other digital making practices:

i) reformatting - where an aspect of reality or text is materially reworked. This brings to mind the re-mixing of image, sound and genre inherent in the intertextual re-presentation of cultural material.

ii) adjacency - the juxtaposition of "two unlike domains ... the closer they are the more stimulating seems their twined presence" (ibid). The idea of contrasting or complementary 'adjacency' is fundamental to the creative process, and editing mirrors this in the ways in which varied shots, clips, music and sounds are artfully stitched together on a timeline in processes of multi-layered matching and sequencing.

iii) surprise - "you begin dredging up tacit knowledge into consciousness to do the comparing" and experience wonder. "Surprise is a way of telling yourself that something you know can be other than you assumed" (ibid). Sennett introduces a welcome affective dimension that helps us understand the fun element in media production, and the wonder and surprise that audiovisual manipulation can engender. There is a sense in which present creative conditions mesh with past experience, precipitating an urge to recast them in concrete form. From clinching the take, to trusting feelings of 'rightness' in editing, recurrent experiences such as these beget confidence, pleasure and arguably, a reflexively literate state of being.

iv) gravity - the recognition that leaps do not defy gravity and constraints are something of a constant. Sennett concedes the inevitable downward arc of the imaginative leap - here articulated as the human or technical hitches and glitches in craft processes, and contingent social conditions. Overcoming unexpected setbacks can require ingenuity, cooperation and some imaginative re-negotiation with the available resources. Film-making then, embraces 'habits of mind' that question, along with a certain independent resourcefulness, attributes that might be seen to be misaligned with a version of literacy packaged as predictable and efficient one-size-fits-all solutions.

It remains to illustrate what any of this means in actual practice. We offer an account of a Clip Club editing session where the children are working with green screen technology fixing shooting imperfections and making decisions on how and where to make their cuts (see Cannon 2013b, at 9' 17"). The have worked collaboratively at the filming stage, and in postproduction they notice that the creased green screen fabric had been imprecisely positioned, making their background uneven in terms of shading and coverage, so an improvisatory mode kicks in. This means using the Cut Away effect - where the overlaid green screen clip is cut diagonally to obscure a visual anomaly - but fixing that problem produces yet another effect, the meaning of which is interpreted literally by the main editor: 'Oh my God, you're 
just going into no-where!'; then, more imaginatively by the actress involved: 'It looks like I'm coming from a different room' (See Figure 1). At that point, the effect is ratified and given narrative integrity by another group member who makes an interpretive claim on the 'mistake' drawing on the popular motif of the 'portal' to another dimension: 'No! make it look like diagonal because then it looks like she's going through some portal door'. The editor at the helm, pleasantly surprised, endorses this suggestion: 'Oh yeah, that is actually kind of a good idea!' which, with tacit agreement, becomes an integral part of the narrative.

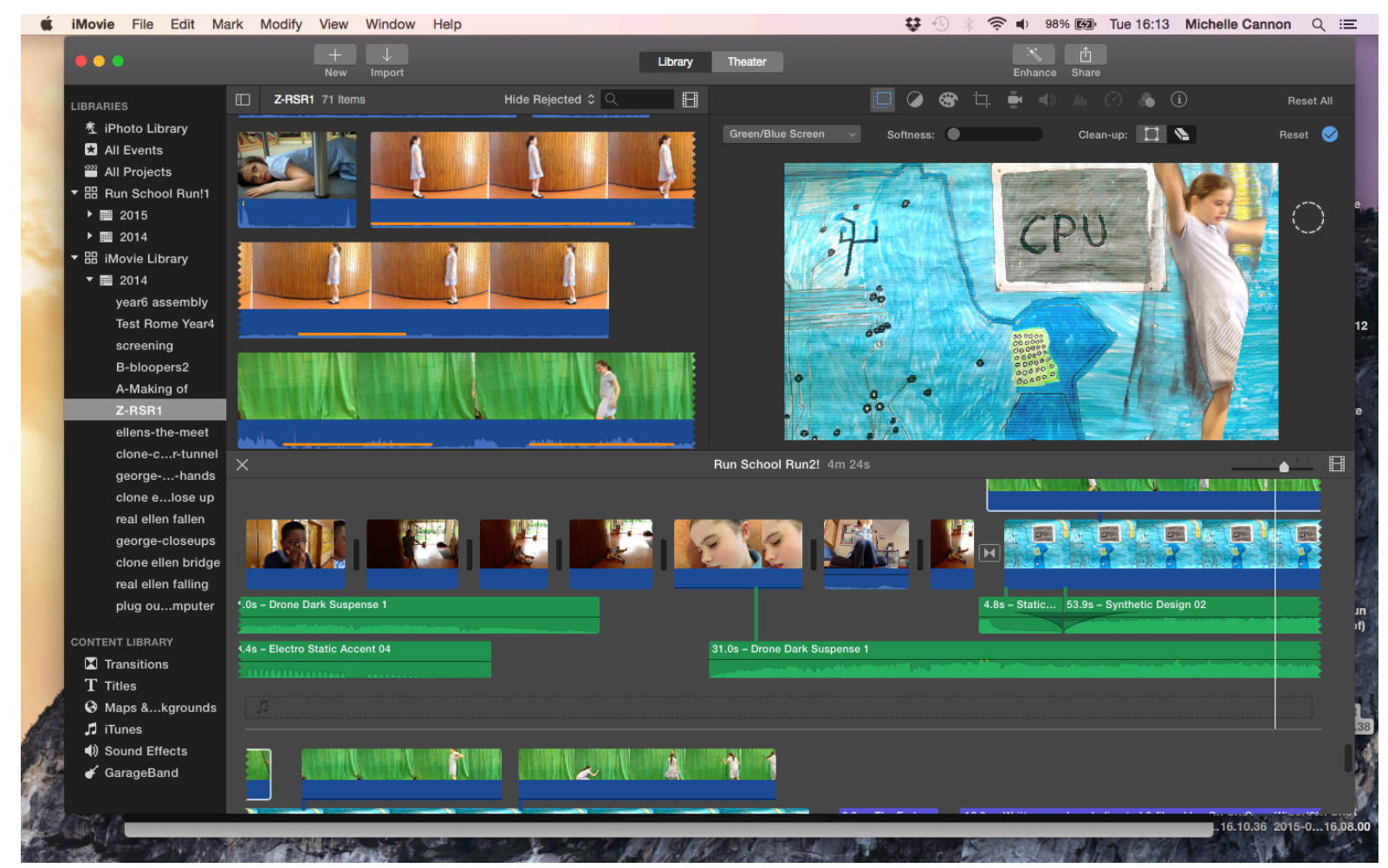

Figure 1: iMovie editing interface featuring the timeline and the Cut Away effect to the right of the viewer pane

Making and adapting visual meanings on-the-fly and taking swift remedial action is possibly one of the characteristics that makes video editing an engrossing experience. We see the actress herself enjoying a sense of creative collusion in this post-production phase, when she intones: 'We're experimenting here people!' as if cooking up some form of alchemy. This simple exclamation, along with the audibly satisfied: We made a decision!' alert us to the pleasures of practical media projects: trying things out, making autonomous decisions on meaning and being open to serendipity.

Feeling such authorial empowerment has to do with praxis: the translation of abstractions into palpable modalities through collective material action. The joint vision of a story to be told that had existed 'darkly' in their imaginations in the weeks prior, was finally crafted and embodied in the viewer pane in processes that involved engaged deliberative action. The video of the children editing testifies to the tangible and sociomaterial elements within this literacy event, and to the dynamic assemblage of editors, bystanders, hardware, software the interface and the audiovisual text. Connections might also be made here with Burn's formulation, digital aletheia (2016), to be explained shortly, where young people are seen to 'bring forth' playful narrative truths in particular media-making environments. Once the interplay between contextual and textual elements is acknowledged as significant, their orchestration, or the pedagogy within this negotiated 'third space' of learning, becomes more salient. 
Beyond the cognitive work, the children in the clip were keenly aware of audience, their two short films had been screened at their school and the making of them had been discussed in an open forum. They thus experienced the vital learning moments during which their texts were released for public consumption and discussed with an audience of peers to explain process and authorial choice. Reflection and display are fundamental aspects of media production as they complete cyclical digital making practices (Cannon 2018). This is where school art and media projects become critical arts practices (Somerson and Hermano 2013) whose ripples provoke dialogic interaction as well as aesthetic impact. We argue that literacy events of this nature are more involving for the learner who engage with 'performances' that have more to do with owning the processes and products of their film-making than with 'performances' associated with data delivery for more remote instrumental ends.

A further complicating factor relates to the 'image' of the image when it comes to the design of literacy programmes. Just as craft practices have languished in the lower league tables of curricular subjects (Frayling 2011), film and media-related subjects are positioned as 'nonfacilitative' (Buckingham 2014). Arguably, this perspective is a residual legacy of Greek classical thinking which, rooted in oral tradition, privileged language and demoted the image as ephemeral (Eisner 2006). Forms of material making were then, and to an extent still are, accorded the lower status of mimicry or manual labour in the spectrum of cultural value. However, in ways that oppose current trends supporting epistemic fixed knowledge in schools, authors such as Sennett (2008) and Crawford (2009) seek to unsettle normative hierarchies of knowledge by championing hands-on making and the feelings of purpose it inspires.

Eisner too, in the sphere of creative arts pedagogy, supports the phronetic knowledge that can be drawn from practical wisdom. For him, this is an important and underestimated realm of knowing that:

... takes into account local circumstances, it weighs tradeoffs, it is riddled with uncertainties, it depends upon judgment, profits from wisdom, addresses particulars, it deals with contingencies, is iterative and shifts aims in process when necessary ... It is not enduring and it is not foundational. Its aim is to arrive at good but imperfect decisions with respect to particular circumstances.

(Eisner 2005, 193)

Over years of practical experience of teaching with and about media, we suggest that phronesis, with its to-ing and fro-ing between action and corrective action, may be useful for naming the kinds of co-learning and teaching practices that permeate digital making environments. The making of videogames and editing of short form video clips requires precisely this kind of experimentation, in order to achieve what Nelson Goodman describes as "the rightness of fit" $(1978,132)$. Goodman's phrase captures artists' ways of negotiating the relationships between qualities in the act of composition (Eisner 2005, 208) in order to get the form or action 'right enough' for the emergence of specific moods, meanings and effects. In this view, questions might be raised as to how this aim is any different from critical thinking associated with print literacy.

Planning matters in most creative endeavours, but just as important are the decisions made 'in flight' (Eisner 2005, 202). Free from 'right or wrong' decision-making, the scope of media arts roles and practices encourages improvisatory critical responses. Eisner articulates the value of arts practice and in so doing suggests that there may be implications for prevailing literacy pedagogies and modes of assessment: 
The arts teach students to act and to judge in the absence of rule, to rely on feel, to pay attention to nuance, to act and appraise the consequences of one's choices and to revise and then to make other choices.

(Eisner 2002, 208)

In terms of demonstrating the recursive power of editing as a process, the relative ease with which the audiovisual can be edited might be framed as an accessible parallel to the editing of writing. Might this be a foothold in the dismantling of sealed standards that congeal around 'schooled' literacies? Our experience as media educators and researchers repeatedly demonstrate that creative media arts engagements that pay attention to digital composition and local context, move literacy on, so that artistry can begin to surface and criticality begin to take shape. The negotiation of playful juxtapositions and multimodal layering are made all the more explicit in the analysis of videogame authorship, further exemplifying pertinent and dynamic literacy events of relevance to children and young people in the here and now.

\section{PLAYFUL LITERACIES}

The two projects considered here both involve young people's production of videogames, in both cases as adaptations of literary texts. In the first, a group of eight Year 9 students made videogames based on selected scenes from Shakespeare's Macbeth, in a project with Shakespeare's Globe [1]. In the second, a variety of groups (PGCE students, school groups, UCL Anglo-Saxon students, workshop participants at the National Videogames Arcade, and drama students in Sydney, Australia), made games based on the Anglo-Saxon poem Beowulf [2].

We might think of these forms of production as literacies firstly in relation to established models of media literacy. An analysis of earlier work using a version of the same software [3] can be found in Buckingham and Burn (2007), which demonstrates how game design by students exemplifies the so-called 3-Cs model of media literacy, consisting of cultural, critical and creative elements (Burn and Durran 2007). The work in the Playing Shakespeare and Playing Beowulf projects exemplifies the same elements.

Firstly, it is embedded again in aspects of gaming culture, as interviews with students revealed. One group of Year 8 students in an East London school, for example, chose music tracks to incorporate into their Beowulf games, and these included music from Skyrim, the fifth instalment in the roleplaying game series The Elder Scrolls (Bethesda Game Studios 2011). This was an appropriate choice since this game is set in a fantasy mediaeval environment, with many elements reminiscent of similar narrative which can be traced back from contemporary games and films, through Tolkien's work, to Beowulf itself (Carr et al. 2006). It's worth noting, however, that the cultural reach of the tracks chosen by the groups extended well beyond games, including references as diverse as Dr Who and Icelandic folksong.

Secondly, in relation to the critical dimension of media literacy, the games involved, as in the prior project, a developing understanding of the textuality of games, and especially the need to interweave narrative and ludic elements, a design process considered further below (Carr et al. 2006).

In relation to creativity, again it was possible to consider how the young game designers adapted and transformed their cultural experience of games into something new through the use of semiotic tools, both technological (the rule-making system of the game software) and conceptual (understandings of rule, economy, narrative and other central features of game design) (Vygotsky1931/1998). This work can be understood as craft skills, but also as 
cultural endeavour that reaches beyond artisan craft in search of valid representations of the world, in this case through building convincing fantasy narratives, a process described by Burn, in the context of arts education, as digital aletheia - a construction of a claim to truth through digital making (Burn 2016).

While the students' game designs in these two projects exemplify these aspects of media literacy, however, they also featured two additional components, extending the reach of what we can consider as literacies. The first is the connection between games and literary texts. The second is the extension of the programming system offered by the software. These new dimensions will be considered next, followed by a discussion of the ways in which such literacies can be seen as playful.

\section{Playful adaptation}

To make a videogame based on Macbeth or Beowulf is self-evidently a work of adaptation, as it would be in the case of a film version. There is no space here to engage with the complex history of adaptation theory (e.g. Hutcheon 2012); but one example will serve to demonstrate what the adaptation of a canonical text into videogame form might mean in terms of literacy.

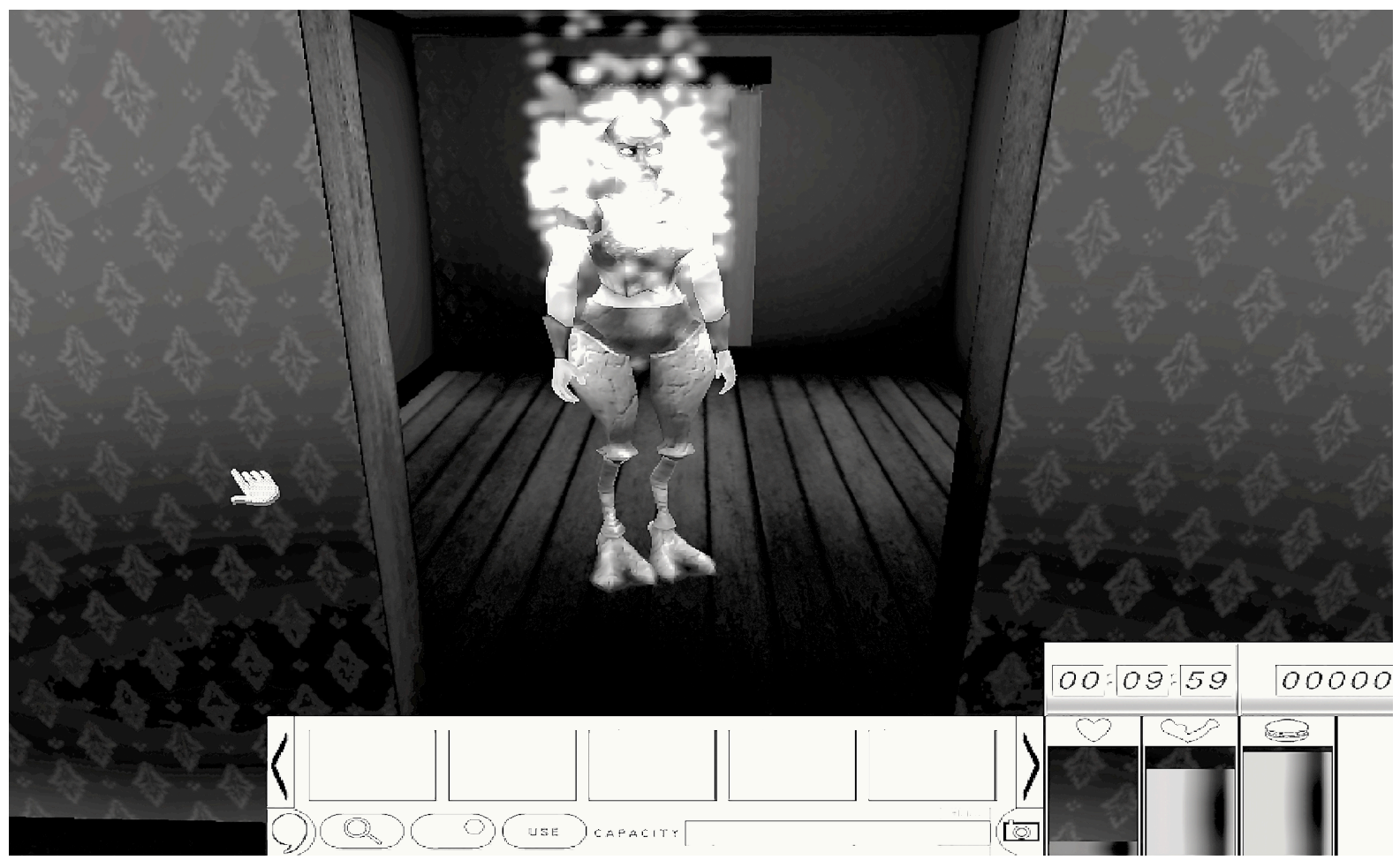

Figure 2: The girls' design for the fiery witch in their Macbeth game.

Year 9 twin girls in the Playing Shakespeare project made a game level based on the events immediately prior to the murder of Duncan (Macbeth, Act 1, scene vii; Act 2, scene ii). They made three specific design choices at odds with the actual sequence of events in the play. The first, critical choice was to include the witches, who do not of course appear in these two scenes. This made a kind of implicit narrative sense, working as a timely reminder of the prophecies for the player, as s/he, in the role of Macbeth, moves towards the murder. However, it was apparent that the inclusion of the witches was motivated by the girls' fascination for these characters. In an earlier experimental session with the software, they had immediately focused on the witches, and discussed how they could represent them in game form, how they could recreate their environment, and which snatches of dialogue they 
might redeploy. Having later been assigned by the teacher the scenes immediately prior to the murder, they determined to include the witches anyway. In this sense, they have disrupted the temporal sequence of the play to shape the game version to their own interests.

The second decision was the design of the witches. The software contains pre-modelled 3D characters which can be selected and placed in the game environment. For Lady Macbeth and Duncan, the girls chose what might be seen as default character models - a mediaeval queen and king. For the witches, however, they went further, using a feature of the software which allows composite models with heads, torsos and legs from different characters. For the witches, they chose the head of 'Mad Scientist', the torso of 'Female Superhero', and the legs of 'Alien', producing a bizarre combination. It is noteworthy that they made only two witches, a link with themselves. They also distinguished the otherwise identical characters by adding special effects: a spouting water effect for one, and a magical fire effect for the other, creating the elemental impression of a watery witch and a fiery witch (Figures 2 and $3)$.

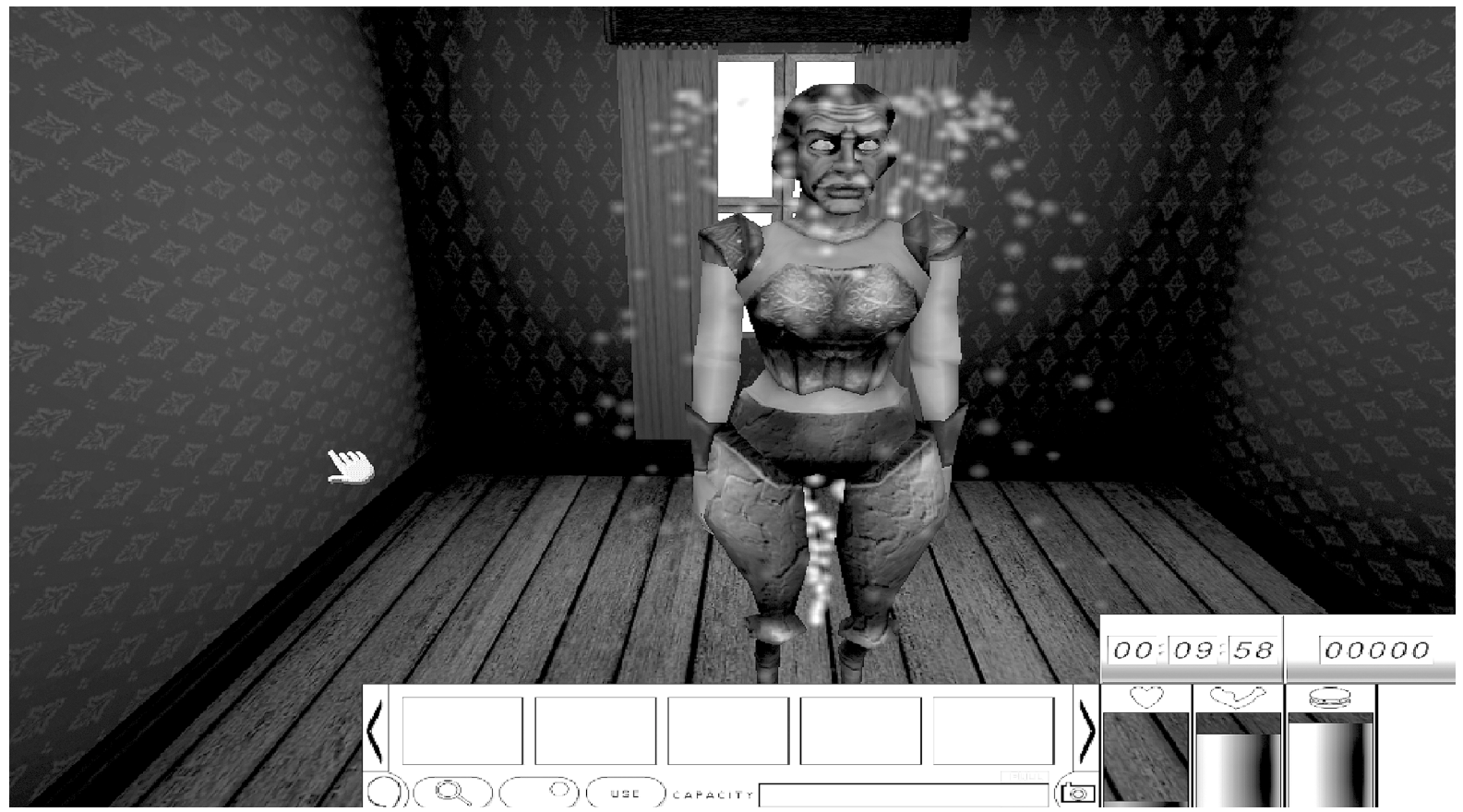

Figure 3: The girls' design for the watery witch in their Macbeth game.

Their second decision related to dialogue choices. One again, in other parts of their game they used pre-recorded dialogue, such as a speech spoken by an actor for Lady Macbeth. The witches were the only characters to which they attached their own voices, recording "Hail to thee, Thane of Glamis" and "Hail Macbeth, thou shalt be king hereafter". Taken together, the animated character models and the recorded speech constitute a double performance, a composite of virtual and vocal embodiment producing the multimodal entities which function as NPCs (non-player characters) in their game level.

The third decision related to the spatial design of their game. The version of Macbeth's castle which they build has three levels: a ground floor, where the Macbeths first appear; Duncan's bedchamber, which is downstairs in the basement; and the rooms housing the witches, which are upstairs. The marked feature of this choice is that it disrupts the usual spatial organisation of the play. The text implies that Duncan's chamber is upstairs, though it does not appear in the play text; while film adaptations which show the murder of Duncan invariably place the chamber upstairs. The girls' contrary spatial design has two effects. One is to elevate the witches, locating them in a mysterious upper domain, which we might read 
as signifying an elevated status, applying Kress and van Leeuwen's proposals for the significance of top and bottom areas in the 'grammar' of visual design (1996). The other effect is to bracket them off from the main narrative trajectory. The player does not have to go upstairs, but can choose to do so as an exploration, or a diversion - an example of the traversal possible in texts which offer multiple routes, termed hypermodality by Lemke (2002).

In general, then, the work of adaptation into videogame has allowed these girls to disrupt the temporal and spatial organisation of the play, and to realise characters as embodied, multimodal entities, all in the service of the elements of the play of most interest to them: powerful, magical female figures. In a way redolent of the Clip Club members' autonomous, playful acts of reinterpretation, we re-invoke the notion of digital aletheia (Burn 2016) which here means careful work with visual and audio digital tools to create representations adequate to their interest and their imaginative reach. 'Adaptation' means a kind of intense reader engagement coupled with a mildly disobedient reading, and a transformation which plays into both the visual aesthetic and the multiple narrative choices typical of videogame design. If it is a literacy which engages with a canonical text in new ways, it is also a form of media literacy in which creativity means attentiveness to the affordances and specificities of game design.

\section{Coding the canon}

The girls' Macbeth level also involved making rules, using an elementary coding interface provided by the software, an account of which can be found elsewhere (Burn 2017). For the Playing Beowulf project, this rule-making system was extended, allowing students to develop an understanding of Boolean logic by using Boolean operators in their rules (Figure 4).

The rule-set shown in Figure 4 is part of a game created by two Year 9 boys in an innerLondon school. They were part of a group which had worked on the story of Beowulf, visited the British Library to see the manuscript, and participated in an afterschool game-making club run by the school's head of ICT and one of the English teachers. The rule, which consists here of multiple conditions (including the Boolean operator "OR"), and resulting actions, specifies that if the player clicks on a map found in a room, or alternatively picks up the map and adds it to the player inventory, then three enemy warriors will appear. In terms of adaptation, this sequence is only loosely related to Beowulf, though the wider narrative of which it is part is more directly linked, adapting the figure of Hrothgar's queen Wealhtheow as an agent obstructing Beowulf's progress to kill Grendel's Mother. In this sequence, however, the three warriors who appear represent generic mediaeval characters blocking the player's progress. The significance of the map for the two boys making the game is that it is one of a class of objects they described as 'secrets': apparently innocent objects which, if discovered and clicked or picked up, had the power to trigger events. This concept is derived from their own gaming culture, but it is here abstracted as an element of the programmed structure of the game. The objects are 'secrets' in a narrative sense - they have magical properties not immediately visible - but they are also 'secret' in terms of the programmed ludic structure of the game, in that their visual appearance conceals a programmed function, so they cannot be distinguished from other objects except by trial and error. The boys could have made their function visible using a highlight tool which would make the objects glow; but they dismissed this idea as it would undermine the secret property they sought to create.

Their discussions about how to build these game mechanics involved a planned division of labour. They decided that one of them would be responsible for the story, and the other for the game mechanics. This idea represents a kind of proto-designer discourse (Burn 2008; de Paula 2016), again derived from their gaming culture. It also echoes a familiar perennial debate in academic game studies, the so-called narratology-ludology debate, about whether 
to conceive games as interactive stories or as games. The answer usually resolved into an agreement that we need to do both, and the better integrated the two, the better the game is (Carr et al. 2006). In the case of the two boys, it soon became apparent that they both fulfilled both roles, effectively integrating both the discourses of game design they deployed, and the structures of narrative and ludic design in their game. The naming of the characters signified a kind of jocular confidence: in the game they appear as stern, anonymous mediaeval warriors - behind stage, as it were, they are labelled by the boys Gary, Billy and Destroyer of Worlds Bob.

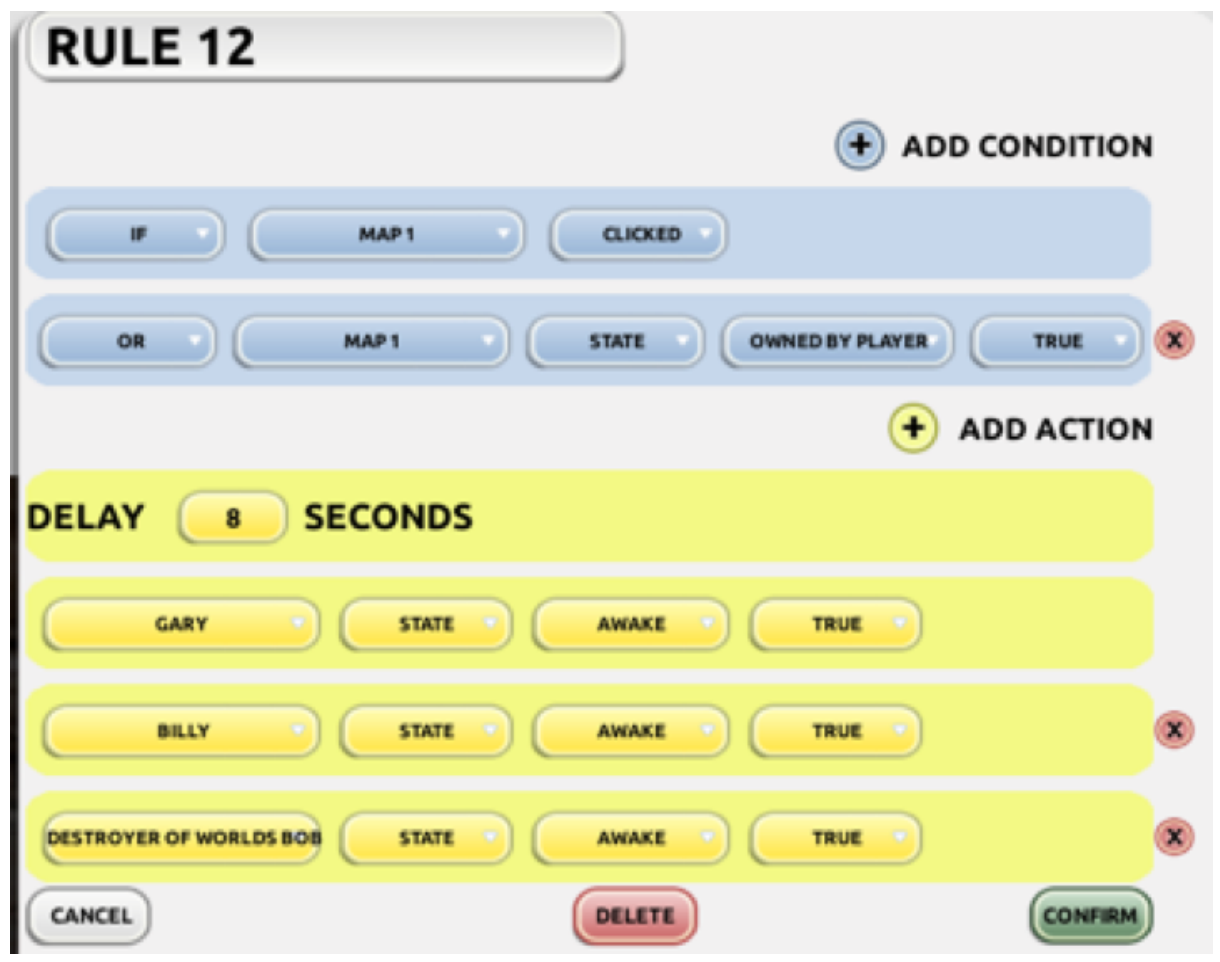

Figure 4: Coding interface of Missionmaker Beowulf.

In what sense, then, does this work count as 'literacy'? Clearly it fulfils the familiar media literacy qualities - it is culturally informed, critically aware of game design practices and textual structures, and creative in its use of semiotic tools in the service of imaginative work. However, the coding element extends the 'literacy' into the domain of computing in schools. Furthermore, it brings the language of coding into immediate proximity with the language of narrative. To 'code' Beowulf means to fuse the grammar of computer-driven events with the grammar of story-telling. In curricular terms, it finds a kind of literacy which spans the English/Media classroom and the computing classroom. While these two curriculum areas are usually remote from each other, it is worth noting that the literacy involved here is not a vague metaphor or synonym for competence. Rather, it is a specific restricted lexicogrammar deployed by students to create narrative and ludic events, properly situated in a sociocultural context.

The final question posed by this section is: in what ways can these literacy practices be seen as playful? Three possibilities will be briefly proposed. Firstly, these games are self-evidently designs for play. There is no space here to elaborate on the kinds of play videogames offer, though from the categories proposed by Caillois (1958/1979) the kinds of play he terms agon (combat) and mimicry (role-play) are particularly appropriate, and connect these activities not only to the study of literary drama but also to practices of educational drama. 
Secondly, the forms of engagement with literature in evidence here are themselves playful. The students play fast and loose with the texts, bending and reshaping them, treating them as plastic material ripe for creative plundering.

Thirdly, the texts themselves are playful in certain ways. Macbeth is, of course, a 'play', a procession of mimicry and dramatic simulation, so the nature of drama itself is a playful fiction, a feature these students highlight in their game designs. Meanwhile, the narrative structure of Beowulf strongly resembles the episodic organisation of agonistically-styled videogames, while the improvisatory work of oral narrative from which the text developed has much in common with the multi-stranded improvisations of the videogame player. In his seminal work on play, Huizinga made this connection between poetry and play, which encapsulates the spirit of these classroom interventions to bring together games and literary texts:

The affinity between poetry and play is not external only; it is also apparent in the structure of creative imagination itself. In the turning of a poetic phrase, the development of a motif, the expression of a mood, there is always a play-element at work. Whether in myth or the lyric, drama or epic, the legends of a remote past or a modern novel, the writer's aim, conscious or unconscious, is to create a tension that will 'enchant' the reader and hold him spellbound. (Huizinga 1938, 132)

The young game designers described in this section, then, are engaged in forms of authorship with many similarities to the practices of animating poetry and video editing. They employ digital tools as 'multimodal mixing desks' (Burn and Parker 2003) and shape transmedia narratives that 'enchant' both maker and audience, holding them 'spellbound' within the storyworld.

\section{CONCLUSION}

This paper has considered the value inherent in literacy practices that craft the multi-sensory into meaningful disclosures, a phenomenon Burn named digital aletheia (2016). We referred to the swirl of critical, creative and cultural influences that shape dynamics around learners and new literacies: the political performative forces, the mobilisation of students' cultural capital, the 'assemblages' of human and non-human actors, the exercise of phronetic judgment, and the relationships between canonical texts and videogames. In Potter's terms, rendering literacy curricula more 'ambitious' and thereby more relevant to learners' lives, means recognizing digital media's plasticity, provisionality and hybridity. Rule-bending rather than rule-binding practices fly in the face of neoliberal discourse predicated on fixed content, absolute standards and the sanctity of print. We need a vision of literacy elastic enough to accommodate the multimodal landscape of digital media, and the range demanded by both heritage culture and popular culture, in order to inform pedagogies adequate to the world our students inhabit. Only once autonomous play and textual improvisation with multiple digital modes have been legitimised in the classroom, will there be any sense of progress towards a dynamic ideological model of literacy.

[1] "Playful Shakespeare: Games, Drama and Literature in Education." Arts and Humanities Research Council, 2011. PI, Andrew Burn.

[2] 'Playing Beowulf: Gaming the Library. Arts and Humanities Research Council, 2015. PI, Andrew Burn.

[3] The software is called Missionmaker, and was originally developed by Immersive Education Ltd as part of an EPSRC-funded project, Making Games, 2002-6. It is now owned by MAGiCAL Projects, part of the DARE research centre at the UCL Knowledge Lab. The version used for Playing Beowulf was developed in Unity by MAGiCAL. 


\section{REFERENCES}

Alanen, L., Brooker, L. and Mayall, B. (Eds.). 2015. Childhood with Bourdieu. Basingstoke: Palgrave Macmillan.

Bazalgette, C. (Ed.). 1989. Primary media education: a curriculum statement. London: British Film Institute.

Bazalgette, C., Parry, B. and Potter, J. 2011. Creative, Cultural and Critical: Media literacy theory in the primary school classroom. Paper presented at the Creative Engagements 7, Mansfield College, Oxford University.

Bezemer, J. and Kress, G. 2016. Multimodality, learning and communication: A social semiotic frame. London: Routledge.

BFI. 2008. Reframing Literacy. London: British Film Institute. Accessed 16 November 2017. http://www.bfi.org.uk/sites/bfi.org.uk/files/downloads/bfi-education-reframing-literacy-201304.pdf

Buckingham, D. 2003. Media Education: literacy, learning and contemporary culture. Cambridge: Polity.

Buckingham, D. 2007. Beyond Technology: Children's Learning in the Age of Digital Culture. London: Routledge.

Buckingham, D. 2014. The Success and Failure of Media Education. Media Education

Research Journal, 4(2): 5-17. Accessed: 16 November 2017.

http://merj.info/wp-content/uploads/2014/01/MERJ_4-2-Editorial.pdf

Buckingham, D. and Burn, A. 2007. Game-Literacy in Theory and Practice, Journal of Educational Multimedia and Hypermedia, 16(3): 323-349.

Burn, A. 2008. "The Case of Rebellion: researching multimodal texts". In The Handbook of Research in New Literacies, Edited by: Coiro, J., Knobel, M., Lankshear, C., and Leu, D. J. eds. 149-177. New York: Laurence Erlbaum.

Burn, A. 2009. Making New Media: Creative Production and Digital Literacies (New Literacies and Digital Epistemologies). New York: Peter Lang.

Burn, A. 2016. "Digital Aletheia: technology, culture and the arts in education". In The Routledge Companion to Music, Technology and Education, Edited by: King, A., Himonides, E. and Ruthmann, A. 3-14. London: Routledge.

Burn, A. 2017. "Games, Films and Media Literacy: frameworks for multimodal analysis." In Researching New Literacies: Design, Theory and Data in Sociocultural Investigation, Edited by: Knobel, M. and Lankshear, C. 169-195. New York: Peter Lang.

Burn, A., and Durran, J. 2007. Media literacy in schools. London: Paul Chapman.

Burn, A., and Parker, D. 2003. Analysing Media Texts. London: Continuum.

Burnett, C. and Merchant, G. 2014. Points of view: reconceptualising literacies through an exploration of adult and child interactions in a virtual world. Journal of Research in Reading, 37(1): 36-50.

Caillois, R. 1958/1979. Man, Play and Games. New York: Schocken Books.

Cannon, M. 2013a. The Clip Club blog. Accessed 20 November 2017.

https://theclipclub.co.uk/

Cannon, M. 2013b. The Clip Club footage. Accessed 20 November 2017.

https://vimeo.com/142087018 (password: wizard)

Cannon, M. 2018. Digital Media in Education: Teaching, Learning and Literacy Practices with Young Learners. London: Palgrave Macmillan.

Carr, D., Buckingham, D., Burn, A., and Schott, G. (2006) Computer Games: Text, Narrative, Play. Cambridge: Polity.

Cope, B. and Kalantzis, M. eds. 2000. Multiliteracies: Literacy learning and the design of social futures. New York: Routledge.

Crawford, M. 2009. The Case for Working with your Hands: Or Why Office Work is Bad for Us and Fixing Things Feels Good. London: Penguin.

de Paula, B. 2016. Discussing Identities through Game-Making: A Case Study. Press Start, 3(1): 66-85. 
Dezuanni, M. 2015. The building blocks of digital media literacy: socio-material participation and the production of media knowledge. Journal of Curriculum Studies, 47(3): 416-439.

Eisner, E. 2002. The Arts and the Creation of Mind. New Haven: Yale University Press. Eisner, E. 2005. Reimagining Schools: The Selected Works of Elliot W. Eisner. Abingdon: Routledge.

Eisner, E. 2006. What Do the Arts Teach? Chancellors Lecture Series, Vanderbilt University, Nashville, Tennessee. Accessed 17 November 2017.

http://www.youtube.com/watch?v=h12MGuhQH9E

FLAG. 2015. Film Literacy Advisory Group. A Framework for Film Education. London: British Film Institute. Accessed 20 November 2017.

http://www.bfi.org.uk/sites/bfi.org.uk/files/downloads/ bfi-a-framework-for-film-educationbrochure-2015-06-12.pdf

Frayling, C. 2011. On Craftsmanship Towards a New Bauhaus. London: Oberon Books. Gee, J. P. 2004. Situated language and learning: A critique of traditional schooling. New York: Routledge.

Gee, J. P. 2015. Literacy and Education. London: Routledge.

Goodman, N. 1978. Ways of Worldmaking. Indianapolis: Hackett Publishing.

Green, B. 2002. A Literacy Project of our own? English in Australia, 134: 25-32.

Gutierrez, K. 2008. Developing a sociocultural literacy in the third space. Reading research quarterly, 43(2): 148-164.

Haas Dyson, A. 1997. Writing Superheroes: Contemporary Childhood, Popular Culture, and Classroom Literacy. New York: Teachers College Press.

Heath, S. B. 1983. Ways with words. Cambridge: Cambridge University Press.

Huizinga, J. 1938/1949. Homo Ludens. London: Routledge.

Hutcheon, L. 2012. A Theory of Adaptation. London: Routledge.

Jewitt, C. 2005. Multimodality, "Reading", and "Writing" for the 21st century. Discourse:

Studies in the cultural politics of education, 26(3): 315-331.

Kress, G. and van Leeuwen, T. 1996. Reading Images: the Grammar of Visual Design.

London: Routledge.

Lankshear, C. and Knobel, M. 2006. New Literacies: Everyday practices and classroom

learning. Maidenhead: McGraw Hill Education / Open University Press.

Latour, B. 2005. Reassembling the social: An introduction to actor-network-theory. Oxford:

Oxford University Press.

Lemke, J. 2002. Travels in Hypermodality. Visual Communication, 1(3): 299-325.

Lievrouw, L. H. and Livingstone, S. eds. 2006. The Handbook of New Media (updated

student edition). London: Sage.

Marsh, J. and Bearne, E. 2008. Moving literacy on: Evaluation of the BFI lead practitioner

scheme for moving image media literacy. Sheffield: UKLA.

Marsh, J. and Millard, E. 2000. Literacy and popular culture: using children's culture in the classroom. London: Paul Chapman.

McDougall, J. and Potter, J. 2015. Curating Media Learning: Towards a Porous Expertise. ELearning and Digital Media, 12(2): 199-211.

Pahl, K. 2009. Interactions, intersections and improvisations: Studying the multimodal texts and classroom talk of six- to seven-year-olds. Journal of Early Childhood Literacy, 9(2): 188210.

Parry, B. 2013. Children, Film and Literacy. London: Palgrave MacMillan.

Potter, J. 2011. New literacies, new practices and learner research: Across the semipermeable membrane between home and school. Lifelong Learning in Europe, XVI(3): 2235.

Potter, J. 2012. Digital Media and Learner Identity: the new curatorship. New York: Palgrave Macmillan.

Potter, J., and McDougall, J. 2017. Digital Media, Culture and Education: Theorising third space literacies. London: Palgrave Macmillan/Springer.

Prensky, M. 2005. Listen to the Natives. Educational Leadership, 63(4): 8-13.

Rosen, M. 1989. Did I hear you write? London: Andre Deutsch 
Sennett, R. 2008. The Craftsman. London: Penguin.

Somerson, R. and Hermano, M. L. 2013. The Art of Critical Making: Rhode Island School of Design on Creative Practice. Hoboken, New Jersey: Wiley.

Street, B. 1995. Social literacies: Critical approaches to literacy in development, ethnography and education. London: Longman.

Street, B. 2003. What's "new" in new literacy studies? Critical approaches to literacy in theory and practice. Current issues in comparative education, 5(2): 77-91.

Thomas, M. ed. 2011. Deconstructing digital natives. London: Routledge.

Vygotsky, L.S. 1931/1998. "Imagination and creativity in the adolescent". In The Collected Works of L.S. Vygotsky, Vol. 5: 151-166. New York: Plenum Press.

Yandell, J. 2014. Classrooms as Sites of Curriculum Delivery or Meaning-making: whose knowledge counts? Forum, 56(1): 147-155. 